\title{
NOAM CHOMSKY E O PODER DA RETÓRICA GLOBAL EM FACE DAS INTERVENÇÕES HUMANITÁRIAS
}

\author{
Jayme Benvenuto Lima Jr.
}

Embora rechaçado por amplos setores da academia - inclusive pelas críticas que faz ao método científico e à postura assumida pela maior parte dos que a integram - entre os anos de 1980 e 1994, Avram Noam Chomsky era o ser humano vivo mais citado do mundo, com quatro mil citações de sua obra relacionadas no Arts and Humanities Citation Index e o oitavo numa lista que incluía autores como Marx e Freud, entre as personalidades mais citadas de todos os tempos. Entre os anos de 1974 e 1992, o autor de orientação crítica foi citado 1.619 vezes de acordo com o Science Citation Index. Até o momento, publicou mais de setenta livros e mais de mil artigos cobrindo áreas que incluem a lingüística, a filosofia, a história, a história das idéias, as ciências cognitivas, a psicologia, a política nacional e internacional (Barsky, 2004, p. 15).

Polêmico, misto de intelectual e ativista político, o autor tem sido um ferrenho crítico da política internacional desde os anos 1960 e, muito em particular, de seu próprio país, os Estados Unidos, ao qual acusa de desenvolver um programa de globalização imperial.

Este artigo está relacionado à sua contribuição teórica com ênfase na análise de situações recentes relacionadas a 
conflitos humanitários em certas partes do mundo. A sua produção teórica - vinculada à militância no campo da política nacional norte-americana e internacional - constitui, portanto, o centro deste trabalho.

Ao construir um painel em que descreve quase à exaustão os chamados "crimes terríveis" cometidos na "nova era" em que os Direitos Humanos e os altos princípios do Direito Internacional seriam utilizados para justificar as intervenções humanitárias do final do século XX e início do século XXI, Chomsky lança luzes sobre o discurso político de governantes, representantes de organizações internacionais, jornalistas e autores no campo da política internacional, visando revelar o que nem todos conseguem ou querem ver.

\section{Uma perspectiva anarquista da política internacional}

Com base em esquemas de análise claramente identifica-

124 dos com a perspectiva teórica anarquista, Chomsky professa a idéia de que há um totalitarismo também no capitalismo administrativo outrora e atualmente praticado, uma vez que orientado por decisões ditadas por condicionantes técnicos e econômicos em países que se autodenominam democráticos. Esta compreensão é importante para entender a crítica feita à política dos Estados Unidos, de meados do século XX aos dias atuais, assim como do Reino Unido - a quem considera sócio prioritário norte-americano na tarefa de manter um império global. Na perspectiva de Chomsky, as guerras vivenciadas no século XX, incluindo a Guerra Fria, representam "uma luta entre os grandes competidores imperialistas por uma fatia dos rendimentos da produção mundial, dessa forma, pelo controle sobre o maior número de trabalhadores" (Barsky, 2004, p. 57).

Como anarquista, nosso autor desconfia das grandes instituições, do Estado, da universidade e de seus funcionários. Defende a liberdade para analisar a política norte-ame- 
ricana com mais rigor que os teóricos tradicionais. Parece justificar o objeto de análise e crítica em particular ao seu próprio país em razão do significado político das decisões internas e externas em que os Estados Unidos tomam parte; mas também em razão do que ele próprio vem a sofrer por seu pensamento radicalmente dissidente dentro da sociedade norte-americana.

Impelido a mostrar continuamente os caminhos nos quais as estruturas opressivas - incluindo o capitalismo, os campos de concentração, as câmaras de gás e as campanhas de limpeza étnica - não acabaram, como se costuma assentir, sua crítica fundamental é às estruturas políticas e econômicas dos nossos dias.

Em seus escritos e nos diversos filmes dos quais tem participado, nosso autor demonstra crer na existência de uma conspiração empresarial transnacional pela manutenção do status quo internacional.

Para entender a avaliação de Chomsky a respeito das atitudes dos Estados Unidos, de seus aliados e de organizações internacionais por eles controladas, é necessário considerar sua visão sobre o projeto de controle internacional, segundo a qual

"estudos realizados já em 1941 concluíam que o objetivo fundamental de longo prazo era que os Estados Unidos se transformassem na potência inquestionável do pós-guerra e agissem de forma tal que limitassem a soberania de qualquer Estado que pudesse interferir na política de adquirir supremacia militar e econômica [...]” (2004a, p. 16).

O programa de controle global estaria em inteira compatibilidade com os gastos norte-americanos em matéria militar: o mesmo que todo o resto do mundo reunido. A seu juízo, os Estados Unidos liderariam uma "grandiosa estratégia imperial" que se valeria da "guerra preventiva", supostamente sustentada pelo Direito Internacional. 
"Os princípios básicos da grandiosa estratégia imperial de setembro de 2002 remontam aos primeiros dias da Segunda Guerra Mundial. Mesmo antes da entrada dos Estados Unidos na guerra, estrategistas e analistas de primeira linha concluíram que no mundo pós-guerra os Estados Unidos buscariam "manter um poder inquestionável” (2004a, p. 21).

Em sua interpretação radical dos acontecimentos das últimas quatro décadas, Chomsky lança suas palavras irônicas e provocativas também sobre as "iniqüidades sociais" cometidas no seu próprio país pelos diversos governos, orientados pela mídia e pelos grupos corporativos que os sustentam.

Na contramão do que o mundo aprendeu a conhecer e louvar sobre os Estados Unidos da América, Chomsky considera seu próprio país um "estado totalitário", não muito diferente de outros com pretensões imperiais, como a Rússia e a China. Colocar os Estados Unidos da América no 126 spotlight de suas críticas tem o sentido consciente de dar correspondência à importância que o país tem no plano mundial como exemplo de democracia.

"In a totalitarian state, it doesn't matter what people think, since the government can control people by force using a bludgeon. But when you can't control people by force, you have to control what people think, and the standard way to do this is via propaganda (manufacture of consent, creation of necessary illusions), marginalizing the general public or reducing them to apathy of some fashion. [...] In a totalitarian society, war is a serious business, and [...] the dictator simply says 'we're going to war' and everybody marches" (Manufacturing consent, 1992).

Sua visão sobre a sociedade norte-americana é certamente resultado do que ele mesmo sofreu durante os quentes anos da Guerra Fria, em que os movimentos sociais contrários à 
guerra do Vietnã e à corrida armamentista se viram constrangidos e perseguidos. Muitas foram as vezes em que ele mesmo foi preso ou teve que prestar contas em tribunais por suas convicções e atividades políticas. No auge da Guerra Fria, mais precisamente em 1971, em debate com Michel Foucault na TV holandesa, Chomsky contraconstrangia o sistema:

"To my knowledge, in the American mass media you cannot find a single socialist journalist, nor a single syndicated political commentator who is a socialist. From the ideological point of view the mass media are almost 100 percent 'state capitalist'. In a sense, we have over here the 'mirror image' of the Soviet Union, where all the people who write in Pravda represent the position which they call 'socialism'. [...] there is the remarkable ideological homogeneity of the American intelligentsia in general, who rarely depart from one of the variants of state capitalistic ideology (liberal or conservative) $[. .$.$] In the capitalist society the mass media are$ capitalist institutions" (Chomsky e Foucault, 2007, p. 75)

Assim vista por ele, a grande mídia é aliada dos grandes estados na ocultação de fatos de interesse de suas sociedades. Seu radicalismo parece ser intencional, diante da perseguição a marxistas, anarquistas e esquerdistas em geral nos Estados Unidos, ao ponto de comparar as atitudes políticas norte-americanas ao fascismo:

"The consequence of this conformist subservience to those in power, as Hans Morgenthau correctly termed it, is that in the United States political discourse and debate have often been less diversified even than in certain Fascist countries, Franco Spain, for example, where there was lively discussion covering a broad ideological range. [...] Much the same was true in Fascist Portugal, where there seem to have been significant Marxist groups in the universities, to mention just one 
example. [...] This conformism (in the USA) was called 'the end of ideology"' (Chomsky e Foucault, 2007, pp. 78-79).

Sua posição anarquista pode ser igualmente sentida no trecho abaixo transcrito, também do debate mencionado, com Foucault:

"I believe [...] that a fundamental element of human nature is the need for creative work, for creative inquiry, for free creation without the arbitrary limiting effect of coercitive institutions, then, of course, it will follow that a decent society should maximize the possibilities for this fundamental human characteristic to be realized. That means trying to overcome the elements of repression and oppression and destruction and coercion that exist in any existing society, ours for example, as a historical residue. $[\ldots .$.$] any form of coercion or repression, any form of$ autocratic control of some domain of existence [...] It can not be justified intrinsically. Rather it must be overcome and eliminated" (Chomsky e Foucault, 2007, p. 38) ${ }^{1}$.

Sua busca de legitimação no passado Iluminista é evidente. Para Chomsky, se o pensamento racional não nos protege necessariamente da política autoritária, "a irracionalidade deixa a porta aberta para qualquer coisa, portanto, especialmente para as piores formas de autoritarismo" (Barsky, 2004, p. 145).

\footnotetext{
1 Contraditando Chomsky, responde Foucault: "If one understands by democracy the effective exercise of power by a population which is neither divided nor hierarchically ordered in classes, it is quite clear that we are very far from democracy. It is only too clear that we are living under a regime of a dictatorship of class, of a power of class which imposes itself by violence, even when the instruments of this violence are institutional and constitutional; and to that degree, there isn't question of democracy for us. [...] I admit to not being able to define, nor for even stronger reasons to propose, an ideal social model for the functioning of our scientific or technological society" (Chomsky e Foucault, 2007, pp. 39-40).
} 


\section{Luzes sobre as intervenções humanitárias recentes}

Chomsky avalia as situações em que as potências ocidentais, à frente os Estados Unidos da América e seu sócio britânico, para adotar sua linguagem, estiveram justificando intervenções humanitárias. Ao tratar das intervenções humanitárias, o nosso autor não se restringe a enquadrar o termo na definição legal constante das convenções internacionais de Direito Humanitário. Considera intervenções humanitárias as ações, embora unilaterais, de potências militares no sentido de retórica e formalmente justificarem a manutenção da paz em regiões conturbadas, tendo como base os princípios de respeito aos direitos humanos e humanitários mais relevantes.

Para tanto, Chomsky baseia seu trabalho nos discursos dos governantes e funcionários de governos e organizações internacionais e na análise de autores e jornalistas de referência no campo da política internacional. Nesse sentido, podemos ver um método próprio - chomskyano - em seu trabalho de coleta e análise de informação documental. Entre os principais veículos jornalísticos de referência por ele consultados estão Newsweek, Guardian, Boston Globe, Independent, Le Monde Diplomatique, Financial Times, Moscow Times, Los Angeles Times, Jerusalem Post, Wall Street Journal, New York Times; enquanto entre as revistas especializadas mais referenciadas estão International Affairs, New York Review, Foreign Affairs, Human Rights Review, Australian Financial Review, NYT Book Review, International Documents, Columbia Journalism Review. O trabalho de Chomsky também considera relatórios produzidos por órgãos governamentais, especialmente dos Estados Unidos (a exemplo de relatórios do Departamento de Defesa) e da Grã-Bretanha, de organismos internacionais, dentre os quais se destacam os relatórios da Otan (Organização do Tratado do Atlântico Norte), do Conselho de Segurança da ONU, do Alto Comissariado das Nações Unidas para os Refugiados, do Alto Comissaria- 
do das Nações Unidas para os Direitos Humanos, da OSCE (Organization for Security and Co-operation in Europe); e de organizações não-governamentais internacionais, como a WOLA (Washington Office on Latin America), a Amnesty International e a Human Rights Watch.

Autores como Samuel Huntington, John Mearsheimer, Michael McGwire, Richard Lloyd Parry, Chalmers Johnson, Johnathan Randall, Richard Butler, Mark Weller, Tim Judah, Ruth Wedgwood, Edward Herman, Benedict Anderson, Mark Riley e o próprio Chomsky constituem importantes referências na análise da política internacional em relação às intervenções humanitárias.

Em livro publicado no Brasil em 2003, intitulado Uma nova geração define o limite: os verdadeiros critérios das potências ocidentais para suas intervenções militares, Chomsky examina a idéia de que o "novo internacionalismo" defendido por Bill Clinton e Tony Blair seria justificado pela intolerância a 130 toda repressão brutal de grupos étnicos. Em tom irônico, o autor reproduz expressões de articulistas e políticos segundo os quais o Estado-nação teria chegado ao fim, havendo em seu lugar uma ordem internacional à qual se teria chegado pelas lições da Segunda Guerra Mundial e pela evolução da humanidade a um ponto em que as desumanidades não mais teriam lugar. Em livros anteriores e posteriores a este, vamos encontrar complementações que incluem outros atores internacionais que evidenciariam uma mesma política imperial global. É o caso, certamente, de Ronald Reagan e dos Bush.

Para Chomsky, a nova ordem internacional tratou de atribuir-se legitimidade exclusiva para agir em nome da comunidade de nações, usando a força sempre que considerasse adequado e em obediência às "modernas noções de justiça”. A propósito, nosso autor critica o sentido de comunidade internacional, embora não pela via tradicional da incapacidade de convivência entre sujeitos cultural e economicamente desiguais, mas pelo recurso consciente à 
retórica, responsável por impedir o diálogo honesto entre os Estados, entre estes e as organizações internacionais, e mesmo dentro das organizações internacionais, por mais nobres que possam ser seus objetivos.

A doutrina da nova ordem internacional global, para Chomsky, resume-se à palavra de ordem: "os tiranos que se cuidem”. Sua análise é focada com primazia nos objetivos anunciados pelos Estados Unidos (e certamente seu "sócio britânico") e pela Otan para a intervenção em diversas partes do mundo com os objetivos anunciados de "garantir a estabilidade da Europa Oriental”; "conter a limpeza étnica"; e "garantir a credibilidade da Otan". Estão no centro de suas atenções o bombardeio à Sérvia pela Otan no final da década dos 1990, as operações indonésias no Timor Leste, a repressão aos curdos por Saddam Hussein e pelos turcos, o financiamento ao terror na Colômbia, os atos criminosos de Israel contra os palestinos, as intervenções em nome da guerra contra o terror no Afeganistão e no Iraque, entre outras situações.

Na perspectiva chomskyana, são as grandes potências ocidentais, mais do que tudo através da Otan, que praticam crimes internacionais (genocídio, crimes contra a humanidade e crimes de guerra) nos dias atuais, sob o manto de construção da democracia e de respeito aos direitos humanos - o que constitui, obviamente, uma inversão na perspectiva tradicionalmente aceita. A estas ações Chomsky contrapõe inúmeros exemplos em que as potências ocidentais toleram ou mesmo estimulam - na medida em que emprestam apoio político, militar e financeiro - as atrocidades cometidas pelos amigos, aqueles que, no exercício dos poderes locais, dão sustentação à política internacional que lhes interessa. É o caso dos amigos turcos, em 1997, sob Clinton:

"Graças ao fornecimento constante de armamento pesado, treinamento militar e apoio diplomático, a Turquia 
conseguiu esmagar a resistência curda, deixando dezenas de milhares de mortos, de dois a três milhões de refugiados e 3.500 aldeias destruídas (sete vezes o Kosovo bombardeado pela Otan)" (2003b, p. 18).

Entre os amigos criminosos, além de Saddam até antes da primeira guerra do Golfo, figuraram Ferdinando Marcos, "Baby Doc" Duvalier, Suharto, Nicolau Ceausescu e Mobutu Sese $\mathrm{Seko}^{2}$, todos personas da mais alta consideração e equivalente apoio político e militar.

A propósito dos chamados amigos terroristas usados em sua luta contra o terror, Chomsky aborda a situação do Afeganistão, em que todo o mundo participara, de uma forma ou de outra, do apoio à intervenção armada de caráter unilateral. O que outros autores vêem como contingência natural da política do mais forte sobre os mais fracos, política, financeira e militarmente, nosso autor vê como conivência 132 interessada em legitimar políticas semelhantes em outras partes do planeta.

"Praticamente todos os governos fizeram o impossível para se aliar à coalizão liderada pelos Estados Unidos, sempre por seus próprios motivos. Assim, um dos primeiros países a se aliar, com grande entusiasmo, foi a Rússia. Por que a Rússia? Porque eles querem autorização para dar continuidade, mais ativamente, às suas próprias atrocidades na Chechênia. A China aliou-se de muito bom grado. Eles ficam encantados por contar com o apoio norte-americano para repressão no ocidente da China. A Argélia, um dos maiores países terroristas do mundo, foi recebida de braços

\footnotetext{
2 "O primeiro chefe de Estado contemplado com uma visita à Casa Branca de Bush I foi Mobutu Sese Seko, do Zaire, outro assassino, torturador e saqueador de primeira linha. Os ditadores sul-coreanos também receberam mão forte de Washington até que o governo militar apoiado pelos Estados Unidos foi finalmente derrubado em 1987 por movimentos populares" (2004, p. 116).
} 
abertos na 'coalizão contra o terrorismo'. [...] Atualmente, há tropas turcas em Cabul, ou logo haverá, pagas pelos Estados Unidos para travar a Guerra contra o Terrorismo. Por que a Turquia está oferecendo soldados? Na verdade, eles foram o primeiro país a oferecer tropas aos Estados Unidos no Afeganistão [...]. Foi por gratidão - porque os Estados Unidos foram o único país que se dispôs a lhes dar apoio maciço em suas próprias enormes atrocidades terroristas no sudeste da Turquia, nos últimos anos. [...] Clinton estava inundando o país de armas. A Turquia tornou-se o principal destinatário de armas do mundo, além de Israel e do Egito" (2005, pp. 21-22)

Por esse critério, os Estados violentos podem agir como quiserem, com a aprovação das classes instruídas e da mídia. Estados com ímpetos imperiais regionais, como a Rússia e a China, se sentiriam cômodos em seguir a doutrina norteamericana de segurança nacional. A China estaria respondendo exatamente como esperado, através do aumento de sua capacidade militar nuclear ofensiva, que obrigaria a Índia a responder da mesma maneira, o que, por sua vez, obrigaria o Paquistão a responder em igual proporção. Logo, essa cadeia atingiria o Oriente Médio e grande parte do resto do mundo. A administração norte-americana estaria, assim, dando exemplo ao resto do mundo ao desenvolver novas armas nucleares, o que certamente faria com que outros viessem a agir da mesma maneira, já que não seria razoável esperar o contrário. Como conseqüência, agora “o mundo é um lugar mais inseguro"(2004a, p. 34).

Em conexão com tais desenvolvimentos, está a idéia de que os grandes estados do mundo são estados terroristas. Nesse aspecto, Chomsky vale-se dos ensinamentos de Santo Agostinho para demonstrar que é tênue a diferença na caracterização de "piratas e imperadores": 
"Santo Agostinho conta a história de um pirata capturado por Alexandre, o Grande, que lhe perguntou: 'Como você ousa molestar o mar?'. 'E como você ousa desafiar o mundo inteiro?', replicou o pirata. 'Pois, por fazer isso apenas com um pequeno navio, sou chamado de ladrão; mas você, que o faz com uma marinha enorme, é chamado de imperador.' A resposta do pirata [...] ilustra com certa exatidão as relações atuais entre os Estados Unidos e vários outros atores no plano do terrorismo internacional: a Líbia, facções da Organização para a Libertação da Palestina (OLP) e outros” (Chomsky, 2006, p. 259).

Para nosso autor o significado original de terrorismo considerado como terrorismo de Estado precisa ser resgatado. Originalmente, estes são atos de violência cometidos pelo Estado, no fim do século XVIII, com o intuito de garantir a submissão popular. Com o passar do tempo, atendendo a interesses 134 dos imperadores de todos os tipos, o termo passou a ser empregado para designar, principalmente, terrorismo de pequena esca$l a$, praticado por pessoas ou grupos (2006, p. 259).

Tal concepção abre caminho, a seu juízo, para a afirmação do princípio segundo o qual:

“quando alguém pratica o terrorismo contra nós ou contra nossos aliados, isso é terrorismo, mas, quando nós ou nossos aliados o praticamos contra outros, talvez um terrorismo muito pior, isso não é terrorismo, é antiterrorismo ou guerra justa" (2005, p. 78).

Sob Clinton aconteceu a tragédia vivida pelo Timor Leste, embora o conflito tenha se iniciado com a invasão indonésia, em 1975, logo após a declaração de independência da antiga colônia portuguesa, resultando na matança de cerca de um terço da população do país e uma "enorme onda de destruição, tortura e terror, repetida em 1999” (Chomsky, 2003b, p. 26). 
No Timor, como no Kosovo, haveria uma tendência a considerar que a comunidade internacional fora forçada a enfrentar um desastre humano produzido em parte por sua própria negligência e teria tido de decidir que preço estaria disposta a pagar para corrigi-lo, quando, de fato, tal catástrofe humanitária não seria produto da negligência das democracias liberais, mas criação delas, na medida em que foram atrocidades cometidas com armas e apoio diplomático dos EUA e da Grã-Bretanha. Para Chomsky, os crimes cometidos no Timor Leste poderiam ter sido facilmente evitados se, como reza a retórica entre as potências, houvesse interesse em evitálos. Tratar-se-ia de uma história de traição e cumplicidade, em relação ao povo do Timor, que acreditara no respeito ao resultado do plebiscito em confirmação de sua independência. Os EUA e seus aliados teriam reagido aos massacres no Timor Leste da mesma forma que em tantas outras situações:

“continuando a fornecer ajuda militar e de outra espécie aos assassinos, mantendo relações militares e fazendo exercícios militares conjuntos, enquanto os protegia de uma interferência internacional" (2003b, p. 112).

A atitude da administração Clinton teria sido resultado de um cálculo político em que os Estados Unidos precisariam manter intocadas suas relações com a Indonésia, um país de grande riqueza mineral e mais de 200 milhões de habitantes, "acima de considerações sobre o futuro do Timor Leste, um pequeno e empobrecido território de 800 mil habitantes em busca de independência" (2003b, p. 88). O paradoxo, aqui, estaria em Clinton sair-se como libertador do Timor Leste ao final da fase mais cruel do conflito.

Quanto à intervenção armada na Sérvia, no mesmo período, Chomsky vê um contraste com a inação no Timor. Descrê da justificativa segundo a qual a Otan estaria, na Sérvia, "lutando porque nenhuma pessoa decente pode assistir ao 
assassinato sistemático de outro povo conduzido pelo Estado”, como afirmou à época Vaclav Havel, o último presidente da Tchecoslováquia e primeiro presidente da República Tcheca. Chomsky lança dúvidas também sobre a veracidade dos argumentos de que a Sérvia estaria praticando genocídio ou crime contra a humanidade antes do ataque da Otan. As atrocidades seriam, na verdade, uma resposta ao ataque ${ }^{3}$. Por seu lado, as forças aliadas não seriam capazes de prestar assistência humanitária no sentido mais apropriado do termo:

"A força aérea que foi capaz de destruir com precisão alvos civis em Novi Sad, Belgrado e Pancevo poucos meses antes não teve capacidade de jogar alimento para centenas de milhares de pessoas ameaçadas de morrer de fome nas montanhas para onde tinham sido enxotadas pelas TNI (forças armadas indonésias), armadas e treinadas pelos Estados Unidos e por seus não menos cínicos aliados" (2003b, p. 60).

A acusação chomskyana de que as razões para "usar a força" no Kosovo "são fracas" e que as potências ocidentais "se apressaram em indiciar Milosevic" por crimes internacionais, comparando-o a Hitler, é sustentada pela idéia de que

"não pode haver dúvida de que as autoridades e as forças de segurança da RFI foram responsáveis por crimes graves. Mas o registro noticiado não dá credibilidade à alegação de que essas não foram as razões dos bombardeios; no caso de atrocidades comparáveis ou muito piores durante esse

\footnotetext{
3 "O Pentágono informou que 'aviões americanos despejaram 1.100 recipientes de bombas em cacho, com 220 mil pequenas bombas, no Kosovo', enquanto 'aviões britânicos despejaram cerca de 500 bombas, cada uma com 147 pequenas bombas'. Bombas em cacho também foram usadas em ataques a alvos civis na Sérvia, por exemplo, num ataque de 7 de maio na cidade de Nis, matando 15 pessoas num mercado e atingindo o principal hospital da cidade. Mas isso não é crime, apenas 'erros cometidos pela Otan', informou ao Conselho de Segurança o promotor do tribunal” (Chomsky, 2003b, p. 125).
} 
período, os EUA e seus aliados não reagiram ou - mais significativamente - mantiveram e até aumentaram seu apoio às atrocidades" (2003b, p. 125).

Para chegar a tal conclusão, Chomsky baseia-se: $1^{\circ}$ ) na constatação de que o Timor Leste constituía, na ocasião, situação muito pior que a da Sérvia, sem que se esboçassem indícios de investigação dos crimes praticados pelos generais indonésios, segundo relatos da mídia; $2^{\circ}$ ) na idéia de que os países ocidentais teriam manipulado as informações sobre o grau das atrocidades como forma de desviar o foco sobre suas próprias atividades ${ }^{4} ; 3^{\circ}$ ) as ações violentas das forças armadas e da polícia iugoslavas, desde fevereiro de 1998, aconteciam mesmo em resposta às atividades separatistas, não sendo sustentável que houvesse um programa de perseguição étnica aos albaneses do Kosovo, naquela ocasião; $4^{\circ}$ ) a intervenção no Kosovo teria sido meticulosamente planejada pela Otan como forma de atribuir-se legitimidade, em detrimento das pretensões da $\mathrm{ONU}^{5-6}$.

\footnotetext{
4 "Analistas do Wall Street Journal concluem que 'a Otan intensificou suas alegações sobre campos de extermínio' quando 'viu uma fatigada imprensa inclinar-se em direção à história oposta: civis mortos pelas bombas da Otan' - e, muito mais importante, a infra-estrutura civil destruída e crimes de guerra, incluindo guerra química e biológica” (Chomsky 2003b, p. 110).

${ }^{5}$ As negociações teriam sido deliberadamente dificultadas com a introdução no texto do acordo de uma "cláusula fatal", que daria às tropas da Otan liberdade para atuar em qualquer parte da Iugoslávia, o que representaria uma perda de soberania inaceitável. Segundo Chomsky, a proposta seria deliberadamente inaceitável, com o objetivo de desacreditar a ONU e fortalecer a Otan, em detrimento também do poder das organizações européias preocupadas com a segurança, a exemplo da OSCE.

${ }^{6}$ Igual tratamento mereceriam as estruturas de segurança européias: "Em vez de seguirem a 'rota da OSCE', com sua prioridade na diplomacia e não na força, o papel europeu é drasticamente reduzido quando um confronto se desloca para a arena da violência, onde os EUA reinam absolutos e onde seu sócio britânico, comparativamente, também leva vantagem. Transferir o assunto para a Otan praticamente assegura esse resultado. Nem a diplomacia nem um uso da força 'menos ameaçador' 'seria aceitável para os EUA' [...] em parte por causa da aversão americana ao multilateralismo e de suas relações hostis com a ONU, mas também porque 'eles estavam decididos a evitar o surgimento de uma estrutura de segurança alternativa na Europa, que poderia desafiar sua autoridade'. O objetivo de Washington era 'de-
} 
"em suma, os monitores da $\mathrm{KVM}^{7}$ foram retirados e uma campanha de bombardeios iniciada, com a expectativa, logo cumprida, de que a conseqüência seria uma súbita escalada da limpeza étnica e de outras atrocidades, depois que a organização responsável por cuidar de refugiados fora privada de recursos. Na doutrina da justificação retroativa, os crimes hediondos que se seguiram agora são considerados, talvez, 'suficientes para justificar' a campanha de bombardeios da Otan" (2003b, pp. 130-131).

A pesada acusação de Chomsky encontra guarida no pronunciamento do Tribunal Penal Internacional ad hoc para a antiga Iugoslávia, que concluiu que

"não há provas reais suficientes da existência de um programa secreto, ou de um consenso tácito da parte Sérvia, para liquidar a população albanesa, expulsá-la ou persegui-la da maneira radical atualmente descrita. [...] Os acontecimentos a partir de fevereiro a março de 1998 não evidenciam um programa de perseguição baseado na etnicidade albanesa. [...] Em 11 de março, o mesmo tribunal decidiu que os 'albaneses no Kosovo não foram nem estão sendo expostos à perseguição de grupos, regional ou nacionalmente, na República Federal da Iugoslávia'” (2003b, p. 128).

Assim sendo, para Chomsky a atitude das potências ocidentais nessas situações foi muito mais que a adoção de "padrões duplos", "incoerência", "virada de costas" para outras crises humanitárias. Também não significou que a comunidade internacional "fez muito pouco" para evitar as

monstrar a utilidade da Otan e seu potencial futuro' enquanto 'mostrava a musculatura política da Otan" (Chomsky, 2003b, p. 142).

${ }^{7}$ Kosovo Verification Mission. 
crises humanitárias, ou que "tolerou" abusos ou "foi incapaz de proteger as vítimas”, conforme comumente a mídia e alguns filmes sobre tais situações têm buscado apontar.

"Na Turquia, no Timor Leste, na Colômbia e em muitos outros lugares, pelo contrário, (a administração Clinton) preferiu aumentá-las (as atrocidades), junto com seus aliados, geralmente vigorosa e decisivamente, fatos que permanecem teimosamente invisíveis para aqueles que compartilham a responsabilidade por esses crimes e preferem dar outro rumo à sua indignação" (2003b, p. 132).

O mesmo padrão de comportamento se aplicaria à Colômbia, a cujo país Chomsky atribui o pior histórico de violação dos direitos humanos da década de 1990, ao mesmo tempo em que é o maior beneficiário da ajuda e do treinamento militar dos EUA para "eliminar" seus inimigos (deles e dos próprios EUA). Certamente, no caso da Colômbia, há a particularidade de que as atrocidades são atribuídas a paramilitares, estreitamente ligados às forças armadas que recebem ajuda e treinamento dos Estados Unidos da América, "todos seriamente envolvidos com o narcotráfico". A questão da plausibilidade das razões apresentadas para as intervenções unilaterais persiste:

“[...] o pretexto se baseia na notável pressuposição, praticamente não questionada, de que os EUA têm o direito de empreender ações militares e travar guerras químicas e biológicas em outros países para erradicar uma lavoura de que não gostam, apesar de, supostamente, as 'modernas noções de justiça' não darem à Colômbia - ou à Tailândia, à China e a muitos outros - o direito de fazer o mesmo na Carolina do Norte para eliminar uma droga muito mais letal que foram obrigados a aceitar (e divulgar) sob a ameaça de sanções comerciais, a um custo de milhões de vidas" (2003, p. 25) 
Como o Iraque "não é nenhum Timor Leste, Kosovo ou Afeganistão”, conforme enfatizou Condoleezza Rice numa certa ocasião - afinal, o petróleo é o grande atrativo da região - a intervenção perdura e perdurará por algum tempo mais, a fim de demonstrar que é Washington quem dá as cartas, "não a ONU ou o povo iraquiano" (2004b, p. 147). O Iraque se encaixa mais que perfeitamente na idéia de criação do inimigo supremo de uma guerra preventiva com interesses ocultos ${ }^{8}$.

A negativa à legitimidade de Israel para invadir territórios palestinos em nome da segurança exclusiva de sua população é outro ponto analisado por Chomsky. Com base em relatórios de organizações internacionais como a Anistia Internacional, a Human Rights Watch e a Organização das Nações Unidas, nosso autor busca demonstrar a irrealidade das argumentações israelenses e norte-americanas sobre a situação no Oriente Médio. A seu ver, o conflito é, na ver140 dade, entre Israel, Palestina e Estados Unidos ${ }^{9}$, razão pela

\footnotetext{
8 "O alvo da guerra preventiva deve ter as seguintes características: 1 . Precisa ser totalmente indefeso. 2. Precisa ter importância suficiente para compensar o esforço. 3. É preciso haver um meio de pintá-lo como a mais terrível e iminente ameaça à nossa sobrevivência" (2004b, p. 23). "Toda vez que o Blair, o Bush, o Clinton, a Madeleine Albright ou alguma outra pessoa conclama a uma guerra contra o Iraque, eles sempre falam do mesmo jeito. Dizem: esse é o pior monstro da história. Como podemos deixar que ele exista? Ele chegou até a cometer o crime supremo: usou gases tóxicos 'contra seu próprio povo'. [...] Ele executou a operação Anfal, que talvez tenha matado cem mil curdos, com o nosso apoio. [...] Ele é um monstro, mas fez o que fez com nosso apoio [...]" porque os EUA o apoiavam e o financiavam (2005, pp. 47-48).

${ }^{9}$ Chomsky constrói um painel agudo sobre as atividades israelenses e norte-americanas na região: "A Anistia Internacional apurou que as FDI, 'aparentemente, chegavam a disparar contra pessoas que ajudavam a remover os feridos', e acrescentou que o motorista de uma ambulância da SCVP 'morreu depois que soldados israelenses lhe atingiram o tórax' enquanto ele tentava remover vítimas. [...] Os helicópteros das FDI são aeronaves americanas pilotadas por israelenses. $\mathrm{O}$ fornecimento desses helicópteros pelos Estados Unidos é essencial, pois 'é um absurdo achar que podemos fabricar helicópteros ou importantes sistemas de armas desse tipo em Israel', informou o ministro da Defesa israelense"(2006, p. 262). "Amplas e bem-feitas são, porém, as coberturas jornalísticas em que os Estados Unidos aparecem fazendo severas advertências aos palestinos, intimidando-os a parar com seus atos terroristas, pois 'não acreditamos que a violência compense'
} 
qual a Palestina não tem tido condições de obter resultados minimamente positivos (2006, p. 260). Sendo assim, imprópria é a atitude norte-americana de coordenar processos de negociação de paz por meio de bons ofícios e negociações diplomáticas (2006, p. 259).

Norman Fairclough chega a conclusões semelhantes ao tratar da emergência de um novo regime nas relações internacionais, em especial ao analisar a segurança internacional e o uso da força, como evidenciado no Kosovo, Afeganistão e Iraque. Ao comparar os discursos de Tony Blair, entre os anos de 1999 e 2002, Fairclough salienta dois aspectos em tais discursos: o impacto global de eventos locais e a idéia de globalização como uma ameaça, mais que uma oportunidade $^{10}$. Em tom irônico, disserta Fairclough a respeito do comportamento de Blair:

"Blair's particular contribution to a new doctrine of international security is framing security within 'globalisation', as an aspect of 'globalisation' alongside the more familiar economic and political aspects. Thus the speech is structured by his own particular tripartite classification of globalisation processes - 'economic, political and security'. 'But globalisation is not just economic. It is also a political and security phenomenon.' This excludes what many representations of 'globalisation' include: 'culture'. Blair talks a lot about 'values', but within his imaginary for changed international relations

[...] e das declarações oficiais lamentando a violência e expressando moderada condenação ao programa de assassinatos israelenses. [...] os Estados Unidos vêm barrando qualquer acordo diplomático há uns trinta anos. O contribuinte norteamericano tem financiado uma das partes: Israel" (2005, pp. 39-40).

${ }^{10}$ Algumas das expressões de Blair nesse sentido: "Many of our domestic problems are caused on the other side of the world. Financial instability in Asia destroys jobs in Chicago and in my own constituency in County Durham. Poverty in the Caribbean means more drugs on the streets in Washington and London. Conflict in the Balkans causes more refugees in Germany and here in the US. These problems can only be addressed by international co-operation" (Fairclough, 2005, pp. 41-63). 
[...]. 'Values' seem to be one thing, 'culture' another: one of the most internationally widespread anxieties about globalisation is that it is a threat to cultural diversity" (Fairclough, 2005).

Pode-se resumir nos seguintes pontos as conclusões chomskyanas sobre a política internacional atual:

1. Os Estados Unidos da América são autores e lideram uma "grandiosa estratégia imperial" que se vale da "guerra preventiva" e de ações repressivas e terroristas pretensamente sustentadas pelo Direito Internacional. O método de dominação do mundo está relacionado à violência com que atua e financia, entendida como "um poderoso instrumento de controle"

2. Os Estados Unidos da América se atribuíram o direito de empreender ações militares e travar guerras químicas e biológicas pelos motivos que consigam justificar, mesmo que não 142 sejam plausíveis. Como corolário dessa afirmação, a soberania dos demais países pode ser ignorada tendo como pretexto a defesa dos direitos humanos.

3. Na política de intervenção humanitária desenvolvida atualmente em diversas partes do mundo, a qualificação de violação a direitos humanos depende de quem seja o acusado. Os amigos criminosos merecem proteção e não se pode cogitar de cometerem violações a direitos humanos, enquanto os que se tornam inimigos merecem a mais severa punição com base nos mais altos princípios de direitos humanos.

4. Está em curso um modelo de globalização controlada da "comunidade internacional", através de meios complexos, que envolvem os diversos países do mundo (independentemente de serem mais ou menos poderosos) em atendimento aos interesses da potência imperial e seus aliados.

5. Ao desenvolver uma estratégia de dominação do mundo com base na idéia de criação do "inimigo supremo" e do armamentismo nacional, a política de Washington estaria estimulando a 
proliferação de armas de destruição em massa no plano internacional e, conseqüentemente, fazendo do mundo um lugar mais inseguro.

6. O verdadeiro caráter da política do mais poderoso país do mundo revela-se não pelo poder da retórica de seus presidentes e diplomatas, mas por suas ações e contradições práticas, muitas vezes encontradas no confronto entre os documentos e discursos oficiais e a observação prática.

7. Os alvos de intervenções humanitárias das potências ocidentais são descartáveis no day after, o que confirmaria o descompromisso com os altos valores de proteção dos direitos humanos em condição universal, conforme retoricamente anunciados.

\section{Chomsky, afinal?}

O trabalho desenvolvido por Chomsky, no campo da política internacional, cumpre o papel de criticar quem poucos ousam fazê-lo: os países mais poderosos do mundo do ponto de vista político, militar e econômico, e muito em particular seu próprio país. Não teria sentido, a seu juízo, e em conformidade com sua perspectiva realista-crítica, apontar a política suja empreendida apenas por países como China e Rússia.

Para nosso autor, o mundo tem duas opções com relação ao uso da força: $1^{\circ}$ ) alguma aparência de ordem mundial, seja a Carta da ONU ou alguma coisa melhor, caso seja possível alcançar certo grau de legitimidade; $2^{\circ}$ ) os estados poderosos fazem o que querem, a não ser que sejam constrangidos de dentro para fora. Para ele, "é sensato lutar por um mundo melhor, mas não alimentar veleidades e ilusões sobre o mundo em que vivemos" (Chomsky, 2003b, p. 157).

Se houver uma saída no atual momento histórico, essa saída seria a população em geral assumir o controle de seu próprio destino, passando a se preocupar com os assuntos de interesse comunitário, guiada pelos valores de solidariedade e comprometimento com os outros (Manufacturing 
consent, 1992). Caso isso não venha a acontecer, o cenário de descontrole das questões sociais será cada vez mais profundo, o futuro é "obscuro e confuso".

Ao introduzir a sociedade em suas preocupações, não apenas como objeto de análise, Chomsky estaria a dizer que as teorias, quando desconectadas da realidade e não discutidas com um público mais amplo, perdem sentido. Seu método próprio de análise tem a finalidade de chegar a públicos amplos.

Assumindo a suposição de que num governo capitalista imperialista as classes operárias e os grupos marginalizados estão sendo oprimidos por uma minoria cada vez menor, "deve-se fundar movimentos que incentivem as pessoas a desenvolver sua própria conscientização e iniciativa para libertar-se".

O desafio da sociedade é imenso, considerando o quadro de análise chomskyano.

\section{Jayme Benvenuto Lima Jr.}

é professor da Universidade Católica de Pernambuco e professor colaborador da Universidade Federal de Pernambuco, junto ao Programa de Ciência Política

\section{Bibliografia}

\section{Livros}

BARSKY, R. F. 2004. Noam Chomsky - A vida de um dissidente. São Paulo: Conrad do Brasil.

CHOMSKY, N. 2003a. Contendo a democracia. Rio de Janeiro: Record. 2003b. Uma nova geração decide o limite: os verdadeiros critérios das potências ocidentais para suas intervenções militares. Rio de Janeiro: Record. . 2004a. "Os dilemas da dominação". In: BORON, Atílio (org.). Nova hegemonia mundial: alternativas de mudança e movimentos sociais. Buenos Aires: Clacso, pp. 15-36. . 2004b. O império americano. Rio de Janeiro: Campus. 
2005. Poder e terrorismo. Rio de Janeiro: Record.

2006. Piratas e imperadores, antigos e modernos. Rio de Janeiro:

Bertrand Brasil.

. 2007. O governo no futuro. Rio de Janeiro: Record.

; FOUCAULT, M. 2007. The Chomsky-Foucault debate on human nature. New York: The New Press.

FAIRCLOUGH, N. L. 2005. "Blair's contribution to elaborating a new doctrine of "international community'". Journal of Language and Politics, vol. 4, $\mathrm{n}^{\mathrm{o}}$ 1, pp. 41-63(23).

MITCHELL, P. R.; SCHOEFFEL, J. (orgs.) 2005. Para entender o poderO melhor de Noam Chomsky. Rio de Janeiro: Bertrand Brasil.

\section{Filmes}

Manufacturing consent: Chomsky and the media. Mark Achbar e Peter Wintonick (diretores). Austrália, Finlândia, Noruega, Canadá: Zeitgeist Films, 1992. 167 min.

On globalization. Rage against the machine. Entrevista com Zach De La Rocha. $11 \mathrm{~min}$.

Poder e terrorismo: Noam Chomsky em nossa época. John Junkerman (diretor). Nova York: First Run Features, 2002. 74 min.

Power versus justice. Fragmentos de debate na TV holandesa em 1971, publicados no Youtube. Parte 1 (06:50 min.); Parte 2 (06:02 min.)

The corporation. Mark Achbar e Jennifer Abbott (diretores). Canadá. 145 min.

\section{Internet}

http://www.chomsky.info/ 
is primarily preconditioned by human emancipation. However, in what conditions do international security and emancipation overlap? The present article intends to explore the question, a topic that is not tackled by the endogenous debate of critical security studies (CSS). An interesting path to be followed seems to be the dialogue between cosmopolitan critical theory and cosmopolitan liberal theory. This article argues that an intersection, or continuum, of these two theories would be possible if CSS focused on dimensions of political liberalism that have been neglected, especially to think about a transnational-based democracy and the possibilities of a transnationalized civil society.

Keywords: Critical security studies; Critical theory; Liberal cosmopolitism; Transnational democracy.

\section{NOAM CHOMSKY E O PODER DA RETÓRICA GLOBAL EM FACE DAS INTERVENÇÕES HUMANITÁRIAS}

JAYME BENVENUTO LIMA JR.

Polêmico, misto de intelectual e ativista político, Avram Noam Chomsky tem sido um ferrenho crítico da política internacional desde os anos 1960, e muito em particular de seu próprio país, os Estados Unidos, o qual acusa de desenvolver um programa de globalização imperial, com sérias conseqüências para a cidadania de milhões de seres humanos do planeta. Este artigo ressalta a contribuição de Chomsky na análise de situações recentes relacionadas a conflitos humanitários em diversas partes do mundo. Ao construir um painel em que descreve quase à exaustão os chamados "crimes terríveis" cometidos na "nova era", Chomsky lança luzes sobre o discurso político de governantes, representantes de organizações internacionais, jornalistas e autores no campo da política internacional, visando revelar o que nem todos conseguem ou querem ver. 
Palavras-chave: Noam Chomsky; Retórica global; Intervenções humanitárias.

\section{NOAM CHOMSKY AND THE POWER OF GLOBAL RHETORIC ON HUMANITARIAN INTERVENTIONS}

A controversial author, mix of an intellectual and an activist, Avram Noam Chomsky has been a hard critic of international politics since the years 1960, and especially of his own country, the United States of America, which accuses of developing a program of imperial globalization, with serious consequences for citizenship of millions of human beings on the planet. This paper emphasizes the contribution of Chomsky on the analysis of situations related to recent humanitarian conflicts in many parts of the world. By making a panel on which he describes nearly to exhaustion the so-called "terrible crimes" committed in the "new era", Chomsky casts light on the political discourse of governors, representatives of international organizations, journalists and authors in the field of international politics, seeking to reveal what not everyone can or want to see.

Keywords: Noam Chomsky; Global rhetoric; Humanitarian interventions.

\section{ASPECTOS TEÓRICOS DAS POLÍTICAS DE CIDADANIA: UMA APROXIMAÇÃO AO BOLSA FAMÍLIA}

WALQUIRIA L. REGO.

$\mathrm{O}$ artigo visa a três objetivos. $\mathrm{O}$ primeiro, destacar muito rapidamente a história recente das teorias dos direitos e da cidadania. O segundo é uma tentativa de compreender o sentido das tensões existentes nas relações entre o Estado e a sociedade civil, a participação política, o mercado e a justiça distributiva. Este conjunto problemático será examinado no âmbito mais amplo da questão democrática. Finalmente, estabelecer as conexões entre as bases normativas de algu- 